\title{
Lista preliminar de trips en plantas ornamentales y malezas en la Región de La Araucanía, Chile
}

\author{
Preliminary list of thrips in ornamental plants and weeds in the Region \\ of La Araucanía, Chile \\ Loreto Manosalva ${ }^{1,2}$, Leonardo Parra ${ }^{1,2}$, Alfonso Aguilera $^{1}$, Ramón Rebolledo ${ }^{1 *}$
}

\begin{abstract}
RESUMEN
Se determinó la presencia de trips en diversas especies vegetales, tanto arbóreas, ornamentales arbustivas y malezas en la Región de La Araucanía durante las temporadas 2005 a 2008. Las especies de trips asociadas a las hojas y flores fueron Heliothrips haemorrhoidalis (Bouché), Frankliniella australis Morgan y Haplothrips leucanthemi (Scharank). Se establecieron nuevos registros de hospederos para la especie $H$. leucanthemi.

Palabras clave: trips, especies arbóreas, plantas ornamentales, maleza.
\end{abstract}

\begin{abstract}
The presence of thrips was determined in diverse trees, ornamental shrubs and weeds in the Region of La Araucanía from 2005 to 2008. The species of thrips associated with leaves and flowers were Heliothrips haemorrhoidalis (Bouché), Frankliniella australis Morgan and Haplothrips leucanthemi (Scharank). New records of hosts for the species $\mathrm{H}$. leucanthemi were established. Key words: trips, arboreal species, ornamental plants, weeds.
\end{abstract}

\section{Introducción}

El orden Thysanoptera comprende alrededor de 5.000 especies de trips, de las cuales 2.000 pertenecen al suborden Terebrantia, y de ésta la familia Thripidae representa el 93\% (Mound \& Teulon, 1995; Mound, 2003). La familia Thripidae con sus subfamilias Thripinae y Heliothripinae destaca por ser la más importante sobre cultivos hortofrutícolas en Chile (González, 1999).

Los hábitos alimenticios de los Thripidae son amplios y variados (fitófagos o carnívoros). Las especies de Terebrantia succionan jugos de hojas, flores y yemas. Numerosas especies florícolas se alimentan casi exclusivamente de néctar y polen, siendo este último necesario para completar su desarrollo y asegurar su fertilidad, lo cual trae como consecuencia la cita de varias especies de trips en flores, en su mayoría de valor ornamental (Mound \& Marullo, 1996; González, 1989; Carrizo et al., 2008). Las especies del suborden Tubulifera comúnmente se ocultan en restos orgánicos alimentándose de hongos, o bien practican la fitofagia combinada con la formación de agallas y la depredación de microartrópodos (Artigas, 1994).

Muchas especies actúan como vectores de patógenos para plantas, tales como bacterias, virus y hongos. Este es el caso de Thrips tabaci Lind. y algunas especies de Frankliniella que transmiten virus produciendo marchitez y torceduras de hojas en tomate, lechuga, tabaco, papas y piñas (González, 1989; Artigas, 1994).

Según Prado (1991a), la importancia económica de los trips es relativamente reducida y su verdadero impacto debería ser estudiado en cada caso en particular, tal como ocurre con Frankliniella australis Morgan y T. tabaci, los que en ciertos casos son motivos de rechazos cuarentenarios. Otro ejemplo es Haplothrips niger (Osborn) (Phlaeothripidae), el cual corresponde a la sinonimia de $H$. leucanthemi (Scharank), del cual existen registros que datan desde 1960 aproximadamente. Esta especie es común en

\footnotetext{
1 Facultad de Ciencias Agropecuarias y Forestales, Universidad de La Frontera. Casilla 54-D. Temuco, Chile. E-mail: ramonr@ufro.cl*Autor para correspondencia.

2 Programa de Doctorado en Ciencias de Recursos Naturales. Universidad de La Frontera. Temuco, Chile.
} 
Norteamérica y Europa; sin embargo, no es extraña su presencia en Chile, ya que dentro de sus hospederos se encuentran leguminosas tales como trébol (Bailey \& Campos, 1962). H. niger es denominado "trips de la alfalfa" y fue catalogada hace algunas décadas como plaga agrícola de las pasturas de alfalfa en la zona central (González et al., 1973).

En las últimas décadas ha cobrado importancia la especie Frankliniella occidentalis (Pergande), conocida como trips de California, la cual es nativa de Norteamérica (González, 1999). En Chile, esta especie fue detectada por primera vez en 1995, en flores de la Región de Valparaíso (González, 1999), y desde su establecimiento se ha transformado en una plaga de gran importancia económica que afecta a frutales, flores y hortalizas, tanto en cultivos bajo condiciones de invernaderos como al aire libre (Brodsgaard, 1989; Estay \& Bruna, 2002). A pesar de causar síntomas como bronceado y plateado, el daño más grave lo realiza como vector del tospovirus de la marchitez manchada del tomate (TSWV), enfermedad que causa manchas y deformaciones severas en los frutos (Salguero et al., 1994).

Este tisanóptero ha sido estudiado en Chile en cuanto a su morfología (Quintanilla, 1984), distribución (González, 1999), biología (González, 1995; González \& Barría, 1999) y manejo (González, 1983; Prado, 1991b; González, 2001; Ripa et al., 2001; Vargas \& Ubillo, 2005; Larraín et al., 2006; Araya et al., 2007); sin embargo, existen pocos trabajos referentes a asociación con sus hospederos. Particularmente para La Araucanía no se conoce la presencia de especies de trips asociadas a sus hospederos especialmente en plantas ornamentales y malezas, siendo el objetivo de este trabajo dar a conocer las especies presentes en ellas.

\section{Materiales y Métodos}

Durante las temporadas 2005 a 2008 (primaveraverano) y cada 15 días se colectaron trips en diversas flores y hojas, tanto de especies arbóreas, arbustivas ornamentales y herbáceas. Los lugares de colecta correspondieron al llano central de la Región de La Araucanía, en diferentes sectores de la comuna de Temuco, donde se revisaron principalmente jardines. También se muestrearon los caminos que unen Temuco con la comuna de Vilcún y localidad de Labranza. En estos dos últimos lugares se muestrearon praderas con alta presencia de Chrysanthemum leucanthemum L. (margarita) y Anthemis cotula
L. (manzanillón). Las muestras fueron colocadas en bolsas plásticas y mantenidas en condiciones de frío hasta su recuento. Como segundo método de colecta, las flores fueron colocadas en alcohol al $75 \%$, para luego ser revisadas en laboratorio, mediante el método extractivo (Prado, 1991b). El número de muestras varió entre 20 y 200, según la especie hospedera. Todo el material colectado, en las diferentes temporadas, fue llevado al laboratorio de Entomología de la Facultad de Ciencias Agropecuarias y Forestales de la Universidad de La Frontera, para su cuantificación, determinación, etiquetado y posterior inclusión en medios preservantes. La determinación de las especies de trips (Terebrantia) presentes en las muestras se llevó a cabo luego de la preparación del material biológico por uno de los autores (Dr. Ramón Rebolledo) en portaobjeto u observación directa bajo el microscopio estereoscópico binocular. Las especies de Tubulifera fueron enviadas a la especialista Raquel Muñoz, Entomóloga del Servicio Agrícola y Ganadero (SAG) para su determinación.

\section{Resultados y Discusión}

Los resultados de las colectas indicaron un elevado número de trips presentes en flores y hojas. Las especies asociadas fueron Heliothrips haemorrhoidalis (Bouché) y Frankliniella australis Morgan, ambas pertenecientes al suborden Terebrantia. Según la determinación de los individuos recolectados de Tubulifera, la especie correspondió a Haplothrips leucanthemi (Scharank) (Tabla 1).

En la Tabla 1 se observa que $H$. haemorrhoidalis fue encontrado en diferentes especies arbóreas, con un promedio de 193 trips/hoja. También se registró su presencia en la especie ornamental arbustiva rododendro (Rododendrum sp.) con un promedio de 200 trips/hoja. Estos resultados coinciden con Prado (1991a) y González (1989; 1996), quienes señalan la presencia de $H$. haemorrhoidalis sobre ornamentales, sin nominar las especies de plantas sobre las que se encuentra presente el trips del palto. El daño causado por esta especie solamente fue de tipo estético, y específicamente, a nivel foliar.

En relación a $F$. australis, esta fue detectada infestando a la maleza diente de león (T. officinale), con un promedio de 30 trips/flor. Esto es coincidente con lo reportado por diversos autores, quienes señalan la presencia del trips de las flores sobre especies pertenecientes a la familia Asteraceae (González, 
Tabla 1. Especies de trips y sus hospederos colectados en el llano central y precordillera de la Región de La Araucanía.

\begin{tabular}{|c|c|c|c|c|}
\hline Especie de trips & Planta hospedera & Órgano de la planta & Lugar de colecta & $\mathrm{N}^{\circ}$ insectos/muestra \\
\hline \multirow{4}{*}{$\begin{array}{l}\text { H. haemorrhoidalis } \\
\text { (Trips del palto) }\end{array}$} & $\begin{array}{l}\text { Gevuina avellana (Mol.) } \\
\text { (Avellano) }\end{array}$ & Hoja & Temuco & 200 \\
\hline & $\begin{array}{l}\text { Drimys winteri J. R. et G. } \\
\text { Foster (Canelo) }\end{array}$ & Hoja & Temuco & 180 \\
\hline & $\begin{array}{l}\text { Laurus nobilis L. } \\
\text { (Laurel de flor) }\end{array}$ & Hoja & Temuco & 200 \\
\hline & $\begin{array}{l}\text { Rododendrum sp. } \\
\text { (Rododendro) }\end{array}$ & Hoja & Temuco & 210 \\
\hline $\begin{array}{l}\text { F. australis } \\
\text { (Trips de las flores) }\end{array}$ & $\begin{array}{l}\text { Taraxacum officinale } \\
\text { Webber } \\
\text { (Diente león) }\end{array}$ & Flor & $\begin{array}{l}\text { Temuco } \\
\text { Labranza }\end{array}$ & 30 \\
\hline \multirow{2}{*}{$\begin{array}{l}\text { H. leucanthemi } \\
\text { (Trips de la alfalfa) }\end{array}$} & $\begin{array}{l}\text { Chrysanthemum leucanthe- } \\
\text { mum L. } \\
\text { (Margarita) }\end{array}$ & Flor & $\begin{array}{l}\text { Temuco } \\
\text { Labranza } \\
\text { Vilcún }\end{array}$ & 92 \\
\hline & $\begin{array}{l}\text { Anthemis cotula } \mathrm{L} \text {. } \\
\text { (Manzanillón) }\end{array}$ & Flor & Temuco & 80 \\
\hline
\end{tabular}

1989; 1996; Prado 1991a). Cabe destacar que no se encontraron ejemplares en especies arbóreas ni ornamentales arbustivas.

H. leucanthemi (trips de la alfalfa) fue encontrado asociado exclusivamente a flores de margarita (C. leucanthemum) y manzanillón (A. cotula), con un promedio de 86 trips/flor. No se detectó la presencia de $H$. leucanthemi en las especies arbóreas y ornamentales arbustivas. La presencia de Haplothrips en estas especies herbáceas no representa un perjuicio económico, ya que se trata de malezas, lo cual coincide con lo señalado por González (1989), quien indicó que esta especie no presenta importancia económica en Chile. A su vez Prado (1991a) la catalogó como plaga detectada, es decir, sin implicancia económica, pese a estar presente en alfalfa, trébol y tomate. Estos resultados constituyen el primer registro de Haplothrips en malezas (margarita y manzanillón) presentes en praderas del sur de Chile, ampliándose el número de hospederos para esta especie tanto en el llano central como en la precordillera de la Región de La Araucanía.

\section{Conclusiones}

Las especies de trips asociadas a plantas ornamentales y malezas, en la Región de La Araucanía, correspondieron a Heliothrips haemorrhoidalis (Bouché), Frankliniella australis Morgan y Haplothrips leucanthemi (Scharank).

Se determinaron dos nuevos hospederos para la especie H. leucanthemi (Scharank), los que corresponden a margarita (Chrysanthemum leucanthemum) y manzanillón (Anthemis cotula).

\section{Agradecimiento}

Los autores agradecen a la Dra. Raquel Muñoz, Ingeniera Agrónoma, Entomóloga del Servicio Agrícola y Ganadero (SAG) por la determinación de la especie Haplothrips leucanthemi Scharank.

\section{Literatura Citada}

Araya, J.; Curkovic T. \& Zárate H.

2007 Mortality of Frankliniella occidentalis (Pergande) (Thysanoptera: Thripidae) by gamma irradiation. Agric. Téc. (Chile) 67: 196-200.

Artigas, J.

1994 Entomología Económica: insectos de interés agrícola, forestal, médico y veterinario (nativos, introducidos y susceptibles de ser introducidos). Eds. Universidad de Concepción (Chile). 1126 p.

Bailey, S. \& L. Campos.

1962 The Thysanoptera of Chile. Publicaciones Centro de Estudios Entomológicos. 4: 19-26. 
Brodsgaard, H.F.

1989 Frankliniella occidentalis (Thysanoptera: Thripidae) a new pest in Danish glasshouse. A review. Tidsskrift Planteavl. 93: 83-91.

Carrizo, P.; Gastelú, C.; Longoni, P. \& Klasman, R. 2008 Especies de trips (Insecta: Thysanoptera: Thripidae) en las flores ornamentales. Idesia 26: 83-86.

Estay, P. \& Bruna, A.

2002 Insectos, ácaros y enfermedades asociadas al tomate en Chile. Instituto de Investigaciones Agropecuarias, La Platina. Santiago, Chile. 111 p.

González, R.; Arretz, P. \& Campos, L.

1973 Catálogo de las plagas agrícolas de Chile. Publ. Cienc. Agric. Univ. Chile, Fac. Agronomía. Santiago, Chile. 68 p.

González, R.

1983 Manejo de plagas de la vid. Publicaciones Ciencias Agrícolas $\mathrm{N}^{\circ}$ 13. Santiago, Chile. 115 p.

González, R.

1989 Insectos y ácaros de importancia agrícola y cuarentenaria en Chile. Editorial Ograma. (Santiago, Chile). 310 p.

González, R.

1995 Una nueva plaga en frutos de carozo y uva de mesa en Chile: Frankliniella occidentalis (Pergande) (Thysanoptera: Thripidae). Rev. Frutícola 16: 107-111.

González, R.

1996 Biología y manejo del trips de California en huertos frutales, Frankliniella occidentalis (Pergande). Publicaciones Universidad de Chile, Santiago. 64 p.

González, R.

1999 El trips de California y otros tisanópteros de importancia hortofrutícola en Chile (Thysanoptera: Thripidae). Serie Ciencias Agronómicas $\mathrm{N}^{\circ} 1$, Universidad de Chile, Santiago. $149 \mathrm{p}$.

González, R. \& Barría, G.

1999 Abamectina: Insecticida-acaricida de origen biológico en el control de la falsa arañita de la vid y del trips de California y degradación de residuos en nectarinos. Rev. Frutícola 20: 5-10.

González, R.

2001 Manejo conjunto del trips de California, Frankliniella occidentalis (Pergande) y la falsa arañita de la vid, Brevipalpus chilensis Baker en uva de mesa. Rev. Frutícola 22: 51-61.
Larraín, P.; Varela, F.; Quiroz, C. \& Grañá, F. 2006 Efecto del color de trampa en la cáptura de Frankliniella occidentalis (Thysanoptera: Thripidae) en pimiento (Capsicum annuит L.). Agric. Téc. (Chile) 66: 306-311.

Mound, L. A. \& D. A. J. Teulon.

1995 Thysanoptera as phytophagous opportunists. In: Thrips Biology \& Mngmt. (B.L. Parker et al. eds.), Plenum Press, N. Y.; pp. 3-19.

Mound, L. A. \& Marullo, R.

1996 The thrips of Central and South America. An Introduction (Insecta: Thysanoptera). Memoirs on Entomol.; Int. V 6. Assoc. Publ. Fla.; USA. 487 pp.

Mound, L.

2003 Thysanoptera. In Resh, V. H.; and Cardé, R. T. (ed.), Encyclopedia of Insect. Academic Press, Amsterdam, pp. 1127-1132.

Prado, E.

1991a Artrópodos y sus enemigos naturales asociados a plantas cultivadas en Chile. Publicaciones Estación Experimental La Platina, Santiago. 203 p.

Prado, E.

1991b Estudio de la población de trips (Thysanoptera: Thripidae) en huertos de carozos. Agric. Téc. (Chile) 51: 131-137.

Quintanilla, R.

1984 Trips, Características morfológicas y biológicas. Especies de mayor importancia agrícola. Editorial Hemisferio Sur S. A. Bs. Aires, Argentina. 60 p.

Ripa, R.; Rodríguez, F. \& Espinoza, F. 2001 El trips de California en nectarinos y uva de mesa. Publicaciones Estación Experimental La Cruz, $\mathrm{N}^{\circ} 53.100$ p.

Salguero, V.E.; Funderburk, J.E.; Mack, T.P.; Beshear, R.J.; \& Olson, S.M.

1994 Aggregation indices and sample size curves for binominal sampling of flower-inhabiting Frankliniella species (Thysanoptera: Thripidae) on greenhouse sweet pepper. Can. Entomol. 123: 989-1000.

Vargas, R. \& Ubillo, A.

2005 Susceptibilidad de Frankliniella occidentalis (Thysanoptera: Thripidae) a insecticidas en la zona central de Chile. Agric. Téc. (Chile) 65: 437-441. 